\title{
The association between serum osmolality and lung function among adults
}

\author{
Z.E.K. Pogson, T.M. McKeever and A. Fogarty
}

\begin{abstract}
The extensive pulmonary vasculature results in the lungs being intimately exposed to circulating blood. As increased serum osmolality may be associated with an increase in proinflammatory activity, this has the potential to result in damage to the lungs and reduced lung function. The objective of the present study was to test the hypothesis that increased serum osmolality is associated with a lower forced expiratory volume in one second (FEV 1 ) and forced vital capacity (FVC).
\end{abstract}

The present study was a cross-sectional study of 10,602 participants in the Third National Health and Nutrition Examination Survey aged $\geqslant 17$ yrs for whom there were adequate data on all outcomes and exposures.

After adjustment for age, smoking and other confounding factors, increased serum osmolality was inversely associated with both FEV 1 and FVC. An increase of $1 \mathrm{SD}$ in serum osmolality was associated with a decrease in both FEV 1 of $19.8 \mathrm{~mL}$ and FVC of $35.3 \mathrm{~mL}$. The constituent assays demonstrated a complex relationship with both FEV 1 and FVC.

Increased serum osmolality was associated with decreased forced expiratory volume in one second and forced vital capacity. If causal, this may have implications for the understanding of the processes that are involved in the pathophysiology of decline in lung function.

\section{KEYWORDS: Chronic obstructive lung disease, epidemiology, respiratory function tests}

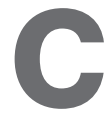
hronic obstructive pulmonary disease (COPD) affects up to 24 million people in the USA, has a global prevalence of 9$10 \%$ in adults aged $>40$ yrs [1] and is a major cause of morbidity and mortality. Although cigarette smoking is the main risk factor for the development of COPD [2], 18\% of adults living in the USA with undiagnosed airflow obstruction have never smoked cigarettes, suggesting that other factors contribute to the pathophysiological processes involved [3]. These include blood glucose level, which has been demonstrated to be inversely related to forced expiratory volume in one second (FEV1) [4-18]. Plasma glucose is one of the molecules that contribute towards serum osmolality (along with sodium, chloride and potassium ions, and urea). Human epithelial cells respond to alterations in the osmolality of their local environment by changes in transmembrane ion transport [19], which may constitute part of the airways' physiological response to a change in the humidity or temperature of inhaled air. In a rat model, an increase in serum osmolality is associated with a systemic increase in proinflammatory cytokine levels [20]. The increase in neutrophils, eosinophils and inflammatory cytokines in induced sputum after dietary salt loading in adults suggests that the pro-inflammatory effect of salt loading extends to the lungs in humans [21], and this effect may be mediated by changes in serum osmolality $[20,22]$. Since COPD is associated with airway inflammation [23-27], it was hypothesised that serum osmolality is inversely related to lung function as measured by FEV1 and forced vital capacity (FVC). This hypothesis was tested by examining the relationship between serum osmolality and its constituent nutrients with lung function using the Third National Health and Nutrition Examination Survey (NHANES III) cross-sectional dataset.

\section{METHODS AND MATERIALS}

\section{Study population}

The present study was conducted using data from the NHANES III, a cross-sectional survey designed to examine the health and nutrition of the noninstitutionalised US population. Data were collected from $>30,000$ participants between 1988 and 1994. Full details of the examination and survey procedures have been published by the National Center for Health Statistics [28]. In these analyses, all participants aged $\geqslant 17$ yrs with complete data for relevant exposure, outcomes and confounding factors were included.
AFFILIATION

Division of Epidemiology and Public Health, University of Nottingham, Nottingham City Hospital, Nottingham, UK.

CORRESPONDENCE

Z.E.K. Pogson

Division of Epidemiology and Public Health

University of Nottingham

Clinical Sciences Building

Nottingham City Hospital

Nottingham

NG5 $1 \mathrm{~PB}$

UK

Fax: 441158231946

E-mail: zara.hoare@

nottingham.ac.uk

Received:

November 012007

Accepted after revision:

February 182008

SUPPORT STATEMENT

The study received funding from Asthma UK.

STATEMENT OF INTEREST

None declared. 
TABLE 1 Characteristics of the study population from the Third National Health and Nutrition Examination Survey, 1988-1994

\begin{tabular}{|c|c|c|}
\hline & Included subjects & Excluded subjects ${ }^{\#}$ \\
\hline Subjects $\mathrm{n}$ & 10602 & 3291 \\
\hline Males & $4921(46.4)$ & $1512(45.9)$ \\
\hline Females & $5681(53.6)$ & $1779(54.1)$ \\
\hline Age yrs & $47.0 \pm 18.9$ & $45.7 \pm 25.1$ \\
\hline Never-smoker & $5448(51.4)$ & $1770(53.8)$ \\
\hline Ex-smoker & $2480(23.4)$ & $779(23.7)$ \\
\hline Current smoker & 2674 (25.2) & $741(22.5)$ \\
\hline \multicolumn{3}{|l|}{ Race/ethnicity } \\
\hline Non-Hispanic White & $4556(43.0)$ & 1215 (36.9) \\
\hline Non-Hispanic Black & $2950(27.8)$ & $1141(34.7)$ \\
\hline $\mathrm{BMI} \mathbf{k g} \cdot \mathrm{m}^{-2}$ & $27.2 \pm 5.8$ & $26.0 \pm 6.1$ \\
\hline FEV 1 L & $2.95 \pm 1.0$ & $3.03 \pm 1.0$ \\
\hline FVC L & $3.74 \pm 1.1$ & $3.71 \pm 1.1$ \\
\hline $\mathrm{FEV}_{1 / \mathrm{FVC}}$ & $0.79 \pm 0.1$ & $0.81 \pm 0.1$ \\
\hline Smoking history pack-yrs & $13.5(4-32)$ & $14.0(3-37)$ \\
\hline Serum osmolality $\mathrm{mmol} \cdot \mathrm{kg}^{-1}$ & $279.7 \pm 6.5$ & $279.8 \pm 7.3$ \\
\hline Serum sodium $\mathrm{mM}$ & $141.1 \pm 2.4$ & $141.0 \pm 2.6$ \\
\hline Serum potassium $\mathrm{mM}$ & $4.1 \pm 0.3$ & $4.1 \pm 0.4$ \\
\hline Serum urea $\mathrm{mM}$ & $5.0 \pm 2.0$ & $5.3 \pm 2.7$ \\
\hline Plasma glucose $\mathrm{mM}$ & $5.7 \pm 2.1$ & $5.9 \pm 2.3$ \\
\hline
\end{tabular}

Data are presented as mean $\pm \mathrm{SD}, \mathrm{n}$ (\%) or median (interquartile range). BMl: body mass index; FEV1: forced expiratory volume in one second; FVC: forced vital capacity

\#: owing to incomplete data collection; ": calculated in ever-smokers alone.

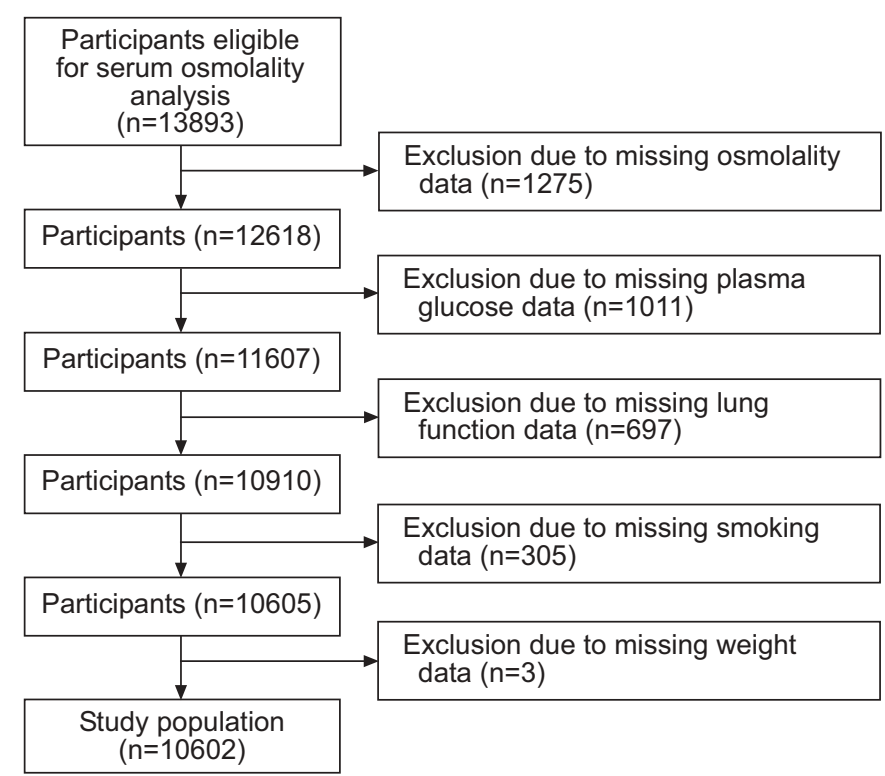

FIGURE 1. Selection of the study population for the Third National Health and Nutrition Examination Survey, 1988-1994.

\section{Data collection}

The questionnaire data were initially collected by trained interviewers who gathered information on a number of factors, including race/ethnicity, medical history, socioeconomic status, use of medication and smoking history. Participants then attended sessions in a mobile examination unit in which blood samples were obtained for biochemical assays. These included serum osmolality, and sodium, potassium, urea and plasma glucose concentrations. The measured serum osmolality assay was an additional blood assay performed once the NHANES data collection was already underway, and the present study population consists of those who were eligible to provide a sample for serum osmolality analysis. Height and weight measurements were obtained and used to calculate body mass index (BMI). Data on lung function were collected in order to provide measures of FEV1 and FVC. Spirometry was supervised by technicians who had completed formal spirometry training. All participants were asked to perform at least five FVC manoeuvres. The FEV1 and FVC used represented the largest values from the acceptable manoeuvres. For a manoeuvre to be acceptable, it had to be a maximal exhalation free of cough, excessive hesitation, leak, an obstructed mouthpiece, variable effort or early termination. 


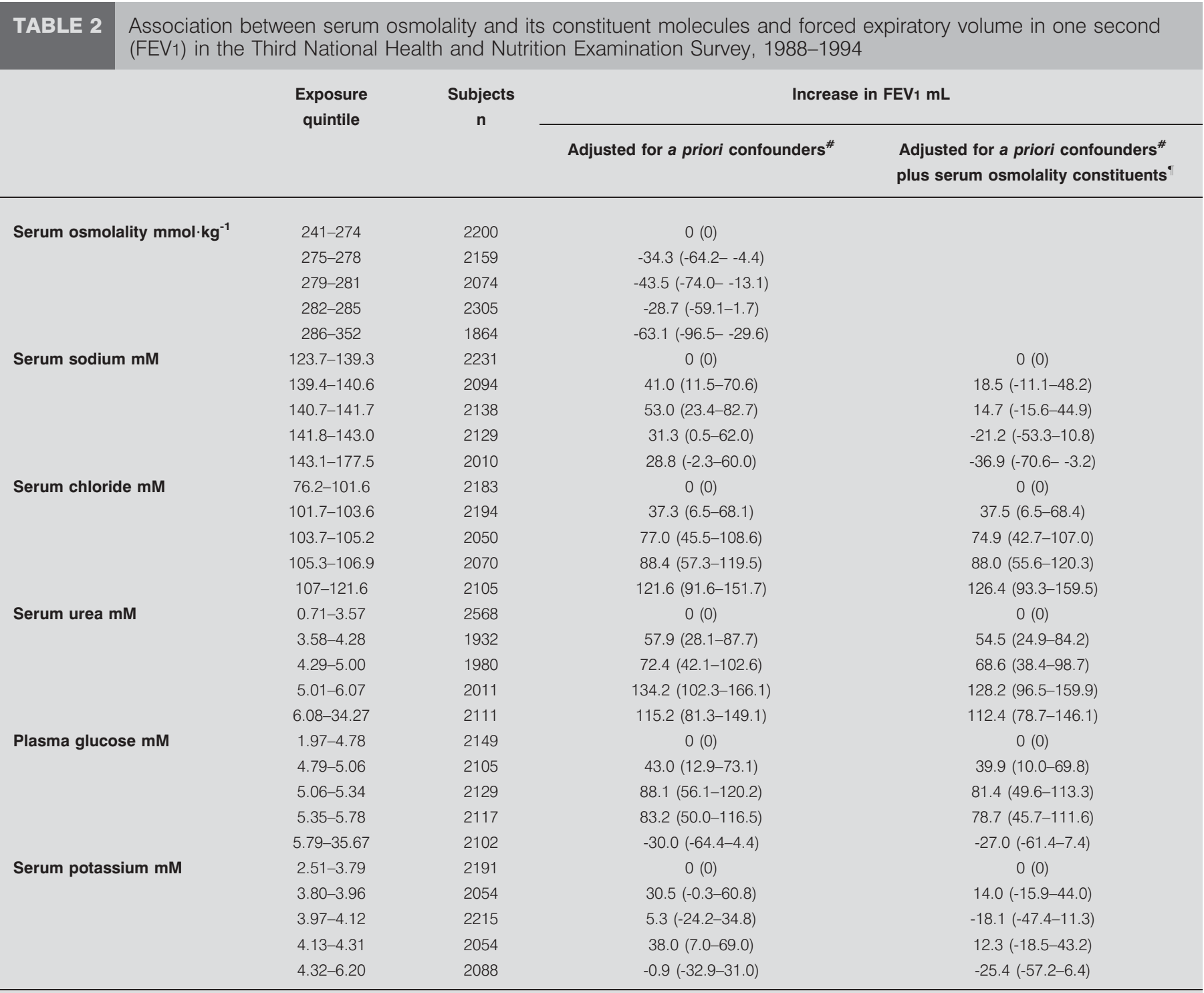

Data are presented as $\beta /$ regression coefficient (95\% confidence interval), unless otherwise stated. ${ }^{\#}$ : age, sex, height, smoking history (in pack-yrs), smoking status, body mass index (categorical) and ethnicity; ": serum sodium, chloride, potassium and urea and plasma glucose.

\section{Statistical analysis}

Using self-reported smoking history, the participants were classified into three groups: never-smokers, ex-smokers, and current smokers. Lifetime cigarette consumption was quantified in pack-years. The association between serum osmolality and lung function (FEV1 and FVC) was the primary outcome of interest, and the associations between the results of the four assays measuring contributors to osmolality (serum sodium, chloride, potassium and urea and plasma glucose) and lung function were examined as secondary outcome measures. The data were analysed using linear regression. The likelihood ratio test was used to assess the presence of linear trends. As serum osmolality exhibited a linear relationship with lung function, it is presented as the change in FEV1 and FVC per $1 \times$ SD increment of exposure. Chloride concentration exhibited a linear relationship with lung function, but sodium, potassium, urea and glucose concentrations did not, and hence the sizes of effect are presented in terms of lung function by quintile of exposure of interest. All analyses were adjusted for a priori confounders, including age, race/ethnicity, BMI, sex, height, smoking status and smoking history. Owing to the nonlinear relationship of BMI with lung function, this was treated as a categorical variable. In addition, the analysis was restricted to individuals with plasma glucose levels of $<7 \mathrm{mM}$ in order to exclude the possibility that any relationship demonstrated was only related to hyperglycaemia. Potential confounders were investigated and included poverty index and serum levels of C-reactive protein, vitamin A, vitamin $E, \beta$ carotene and vitamin $\mathrm{C}$. They were only included in the model if this resulted in a change in the measure of effect of $\geqslant 10 \%$. Data were considered significant if the $p$-value was $<0.05$. Whether there was any effect modification of the association between osmolality and lung function by smoking status was investigated. Owing to the complex multistage probability 
TABLE 3 Association between serum osmolality and its constituent molecules and forced vital capacity (FVC) in the Third National Health and Nutrition Survey Examination, 1988-1994

\begin{tabular}{|c|c|c|c|c|}
\hline & \multirow{2}{*}{$\begin{array}{l}\text { Exposure } \\
\text { quintile }\end{array}$} & \multirow{2}{*}{$\begin{array}{c}\text { Subjects } \\
n\end{array}$} & \multicolumn{2}{|c|}{ Increase in FVC mL } \\
\hline & & & Adjusted for a priori confounders ${ }^{\#}$ & $\begin{array}{l}\text { Adjusted for a priori confounders }{ }^{\#} \\
\text { plus serum osmolality constituents }\end{array}$ \\
\hline \multirow[t]{3}{*}{ Serum osmolality $\mathbf{m m o l} \cdot \mathbf{k g}^{-1}$} & $241-274$ & 2200 & $0(0)$ & \\
\hline & $275-278$ & 2159 & $-63.8(-99.8--27.7)$ & \\
\hline & $286-352$ & 1864 & $-114.5(-154.7--74.3)$ & \\
\hline \multirow[t]{4}{*}{ Serum sodium mM } & $123.7-139.3$ & 2231 & $0(0)$ & $0(0)$ \\
\hline & $139.4-140.6$ & 2094 & $56.1(19.4-92.7)$ & $24.9(-11.9-61.5)$ \\
\hline & $140.7-141.7$ & 2138 & $78.7(42.4-115.0)$ & $28.5(-8.5-65.4)$ \\
\hline & $141.8-143.0$ & 2129 & $48.5(11.6-85.5)$ & $-19.8(-58.2-18.6)$ \\
\hline \multirow{2}{*}{ Serum chloride $\mathrm{mM}$} & $105.3-106.9$ & 2070 & $116.3(79.0-153.6)$ & $108.9(70.1-147.6)$ \\
\hline & $107-121.6$ & 2105 & $152.3(115.6-188.9)$ & $150.3(110.0-190.6)$ \\
\hline \multirow[t]{5}{*}{ Serum urea $\mathrm{mM}$} & $0.71-3.57$ & 2568 & $0(0)$ & $0(0)$ \\
\hline & $3.58-4.28$ & 1932 & $58.4(22.8-94.0)$ & $52.6(17.3-88.0)$ \\
\hline & $4.29-5.00$ & 1980 & $99.3(62.7-135.8)$ & $93.0(56.7-129.4)$ \\
\hline & $5.01-6.07$ & 2011 & $151.3(112.8-189.7)$ & $142.4(104.2-180.6)$ \\
\hline & $6.08-34.27$ & 2111 & $117.4(76.2-158.6)$ & $112.2(71.3-153.2)$ \\
\hline \multirow[t]{4}{*}{ Plasma glucose mM } & $1.97-4.78$ & 2149 & $0(0)$ & $0(0)$ \\
\hline & $4.79-5.06$ & 2105 & 62.6 (26.4-98.9) & $58.0(22.1-94.0)$ \\
\hline & $5.06-5.34$ & 2129 & $102.2(64.0-140.4)$ & $93.0(55.1-131.0)$ \\
\hline & $5.35-5.78$ & 2117 & $85.0(45.5-124.6)$ & $78.2(39.0-117.5)$ \\
\hline
\end{tabular}

Data are presented as $\beta /$ regression coefficient (95\% confidence interval), unless otherwise stated. ${ }^{\#}$ : age, sex, height, cigarette smoking history (in pack-yrs), smoking status, BMI (categorical) and ethnicity; " : serum sodium, chloride, potassium and urea and plasma glucose.

sample design of the NHANES III, estimates were calculated accounting for the survey design.

In a secondary analysis, the relationship between serum osmolality and FEV1 was investigated for a nonlinear association using fractional polynomials [29]. Briefly, in this method, various models are explored and the two polynomial terms which best fits a nonlinear relation between FEV1 and osmolality are selected. However, this method does not permit adjustment for the complex sampling frame used to collect data for the NHANES.

\section{RESULTS}

A total of 13,893 individuals were eligible to provide a sample for serum osmolality measurement. Of these, 10,602 (76\%) participants provided complete data for analysis and so constitute the study population. Reasons for exclusion are shown in figure 1 . The present study population was similar to the excluded population in terms of demographic characteristics (table 1). The only significant differences were that the study population was older $(p=0.001)$ and less likely to be from a non-Hispanic black population $(\mathrm{p}<0.001)$.

Serum osmolality was significantly associated with a decrease in FEV1 of $19.8 \mathrm{~mL}$ (95\% confidence interval (CI) -30.3- -9.3) and FVC of $35.3 \mathrm{~mL}(95 \% \mathrm{CI}-47.9--22.7)$ per $1 \times$ SD increase in serum osmolality. Restriction of the analysis to individuals with plasma glucose levels of $<7 \mathrm{mM}$ resulted in a decrease in FEV1 of $14.8 \mathrm{~mL}(95 \% \mathrm{CI}-26.0--3.6)$ and FVC of $26.3 \mathrm{~mL}(95 \%$ $\mathrm{CI}-39.5-13.1)$ per $1 \times \mathrm{SD}$ increase in serum osmolality.

The associations of serum osmolality, serum sodium, potassium, urea and chloride levels and plasma glucose level with FEV1 and FVC are presented in tables 2 and 3, respectively. This showed complex associations between the exposure of interest and FEV1 and FVC. Mutual adjustment for the effect of 


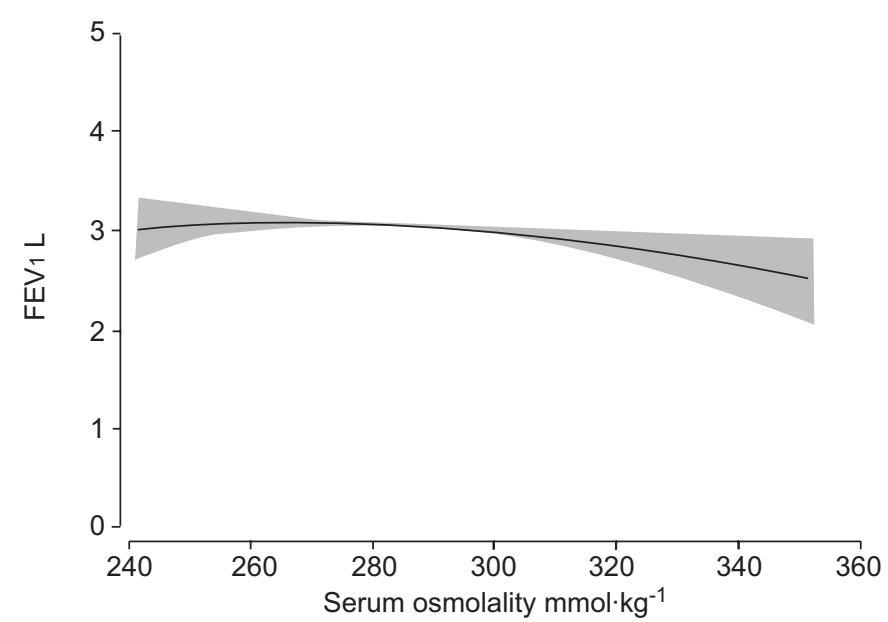

FIGURE 2. Fractional polynomial model $(-2,-2)$ of the relationship between serum osmolality and forced expiratory volume in one second (FEV 1 ), with adjustment for age, sex, height, cigarette smoking history (in pack-yrs), smoking status, body mass index (categorical) and ethnicity ( $\square$ : 95\% confidence interval).

all of the constituents that contribute to serum osmolality suggests that serum sodium level is inversely associated with FEV1, whereas serum urea and chloride levels are positively associated with FEV1, with similar relationships being observed for FVC, with the addition of an inverse association with increasing plasma glucose level.

There was no effect on these results after adjusting for the potential confounding effects of poverty index and serum levels of C-reactive protein, vitamin A, vitamin $\mathrm{E}, \beta$-carotene and vitamin $C$. There was no effect modification of the association between serum osmolality and either FEV1 or FVC by smoking status. There was no significant association between serum osmolality and the FEV1/FVC ratio (data not presented).

When the relationship between serum osmolality and FEV1 was examined using fractional polynomials, it was found that elevated serum osmolality remained a significant predictor of decrease in FEV1 $(p=0.002)$, although this relationship was attenuated at lower serum osmolalities, as demonstrated in figure 2 .

\section{DISCUSSION}

The present study of a cross-sectional population of adults from the USA demonstrated that increasing serum osmolality is associated with decreased lung function in a generally linear relationship, with a decrease of $19.8 \mathrm{~mL}$ for FEV1 and $35.3 \mathrm{~mL}$ for FVC per $1 \times$ SD increase in serum osmolality after adjusting for likely confounding factors. There was a complex association between the individual components of osmolality and lung function. However, when all of the constituents were adjusted for, serum urea and chloride ion concentration were positively associated with lung function and serum sodium and plasma glucose concentration were negatively associated with lung function.

The strength of the present study lies in its use of biological markers of serum osmolality and physiological measurements of lung function in a well-defined population, ignorant of the hypothesis being tested. NHANES III had a high participation rate, with 86 and $78 \%$ of those invited, participating in the questionnaire survey and medical examination, respectively [28]. Complete data were available for $76 \%$ of those who were eligible to participate. As those who provided complete data were similar to those who did not, it was not considered likely that selection bias would influence the present observations. One limitation of the present study is its cross-sectional design, which is unable to establish causality and susceptible to reverse causality. It was considered unlikely that reverse causality is the explanation for the association between higher serum osmolality and lower lung function; indeed, it would be anticipated that the increased ventilation associated with higher lung function would lead to greater loss of water from the airways and hence an increase in serum osmolality. It was also not possible to exclude the possibility of residual confounding from environmental exposures, such as recent infection or pollution, which may impact upon both serum osmolality and lung function.

To the best of the present authors' knowledge, this is the first report of an inverse association between serum osmolality and FEV1 and FVC, and it is important to consider the biological plausibility of this observation and its consistency with other data. Cells lining the human airways respond to hypertonicity with changes in ion transfer and membrane conductance, and it has been speculated that airway cells might play a role as an osmotic transducer, sensing and responding to changes in their local osmotic environment [19]. Evidence that increased extracellular osmolality is associated with pro-inflammatory effects is provided by studies manipulating serum osmolality using salt-loading in rats, in which an increase in serum osmolality resulted in an increase in levels of pro-inflammatory cytokines, such as interleukin- $1 \beta$, that was sustained after rehydration [20]. Further in vitro studies support the concept that high extracellular fluid osmolality modifies neutrophil activity and leukotriene production, and that this is a consequence of changes in extracellular osmolality rather than changes in glucose concentration [30]. Thus changes in osmolality have the potential to modify the activity of the immune system with pro-inflammatory effects. The fact that, in the present study, adjusting for levels of serum C-reactive protein, a marker of systemic inflammation, did not affect the results suggests that, if a rise in serum osmolality were proinflammatory, this effect might possibly be localised to the airways, or alternatively mediated by pathways not measured by C-reactive protein. The concept that pulmonary inflammation can be mediated by changes in serum osmolality is consistent with the observation that dietary salt-loading (which may increase serum osmolality [22]) increased the amount of both inflammatory cells and cytokines in the sputum of adults with exercise-induced asthma [21]. Since COPD, a disease defined by decreased lung function, is associated with airway inflammation [23-27], it was speculated that an increase in serum osmolality might play a role in the pathophysiology of accelerated loss of lung function, although the absence of any effect on the FEV1/FVC ratio suggests that this effect is unlikely to result in an obstructive lung defect in the absence of other risk factors

The relationships between lung function and the molecules that contribute to serum osmolality are more complex. 
This may be a consequence of the fact that the individual contributions of the molecules that contribute to serum osmolality can be difficult to quantify precisely, as demonstrated by the observation that calculated osmolality varies from directly measured osmolality by up to $35 \%$ [31], or that the important exposure is the total serum osmolality rather than that of a single constituent molecule. The present data provide a potential mechanism to account for the consistent inverse association between blood glucose level and lung function reported in numerous cross-sectional studies [4-18] since blood glucose contributes towards total serum osmolality. In order to clarify the nature of the relationship between osmolality and lung function, prospective studies with adequate information regarding potential confounding factors are required since cross-sectional associations identified between exposure and lung function do not necessarily indicate the existence of an association with decline in lung function [32].

In conclusion, it has been demonstrated for the first time that increasing serum osmolality is associated with lower lung function. This provides a potential mechanism to explain the previously observed relationship between glucose and lung function. This observation is novel and deserves further investigation.

\section{REFERENCES}

1 Halbert RJ, Natoli JL, Gano A, Badamgarav E, Buist AS, Mannino DM. Global burden of COPD: systematic review and meta-analysis. Eur Respir J 2006; 28: 523-532.

2 Mannino DM, Homa DM, Akinbami LJ, Ford ES, Redd SC. Chronic obstructive pulmonary disease surveillance United States 1971-2000. MMWR Surveill Summ 2002; 51: $1-16$.

3 Coultas DB, Mapel D, Gagnon R, Lydick E. The health impact of undiagnosed airflow obstruction in a national sample of United States adults. Am J Respir Crit Care Med 2001; 164: 372-377.

4 Burchfiel CM, Curb JD, Sharp DS, et al. Distribution and correlates of insulin in elderly men. The Honolulu Heart Program. Arterioscler Thromb Vasc Biol 1995; 15: 2213-2221.

5 Cooper BG, Taylor R, Alberti KG, Gibson GJ. Lung function in patients with diabetes mellitus. Respir Med 1990; 84: 235-239.

6 Davis WA, Knuiman M, Kendall P, Grange V, Davis TM. Glycemic exposure is associated with reduced pulmonary function in type 2 diabetes: the Fremantle Diabetes Study. Diabetes Care 2004; 27: 752-757.

7 Heimer D, Brami J, Lieberman D, Bark H. Respiratory muscle performance in patients with type 1 diabetes. Diabet Med 1990; 7: 434-437.

8 Katoh J, Hara Y, Kurusu M, Miyaji J, Narutaki K. Cardiorespiratory function as assessed by exercise testing in patients with non-insulin-dependent diabetes mellitus. J Int Med Res 1996; 24: 209-213.

9 Lange P, Groth S, Kastrup J, et al. Diabetes mellitus, plasma glucose and lung function in a cross-sectional population study. Eur Respir J 1989; 2: 14-19.

10 Lawlor DA, Ebrahim S, Smith GD. Associations of measures of lung function with insulin resistance and
Type 2 diabetes: findings from the British Women's Heart and Health Study. Diabetologia 2004; 47: 195-203.

11 Lazarus R, Sparrow D, Weiss ST. Impaired ventilatory function and elevated insulin levels in nondiabetic males: the Normative Aging Study. Eur Respir J 1998; 12: 635-640.

12 Lazarus R, Sparrow D, Weiss ST. Baseline ventilatory function predicts the development of higher levels of fasting insulin and fasting insulin resistance index: the Normative Aging Study. Eur Respir J 1998; 12: 641-645.

13 McKeever TM, Weston PJ, Hubbard R, Fogarty A. Lung function and glucose metabolism: an analysis of data from the Third National Health and Nutrition Examination Survey. Am J Epidemiol 2005; 161: 546-556.

14 Mori H, Okubo M, Okamura M, et al. Abnormalities of pulmonary function in patients with non-insulin-dependent diabetes mellitus. Intern Med 1992; 31: 189-193.

15 Sandler M, Bunn AE, Stewart RI. Cross-section study of pulmonary function in patients with insulin-dependent diabetes mellitus. Am Rev Respir Dis 1987; 135: 223-229.

16 Sandler M. Is the lung a "target organ" in diabetes mellitus? Arch Intern Med 1990; 150: 1385-1388.

17 Strojek K, Ziora D, Sroczynski JW, Oklek K. Pulmonary complications of type 1 (insulin-dependent) diabetic patients. Diabetologia 1992; 35: 1173-1176.

18 Walter RE, Beiser A, Givelber RJ, O'Connor GT, Gottlieb DJ. Association between glycemic state and lung function: the Framingham Heart Study. Am J Respir Crit Care Med 2003; 167: 911-916.

19 Willumsen NJ, Davis CW, Boucher RC. Selective response of human airway epithelia to luminal but not serosal solution hypertonicity. Possible role for proximal airway epithelia as an osmolality transducer. J Clin Invest 1994; 94: 779-787.

20 Summy-Long JY, Hu S, Pruss A, Chen X, Phillips TM. Response of interleukin-1 $\beta$ in the magnocellular system to salt-loading. J Neuroendocrinol 2006; 18: 926-937.

21 Mickleborough TD, Lindley MR, Ray S. Dietary salt, airway inflammation, and diffusion capacity in exerciseinduced asthma. Med Sci Sports Exerc 2005; 37: 904-914.

22 Brooks VL, Scrogin KE, McKeogh DF. The interaction of angiotensin II and osmolality in the generation of sympathetic tone during changes in dietary salt intake. An hypothesis. Ann NY Acad Sci 2001; 940: 380-394.

23 Birring SS, Brightling CE, Bradding P, et al. Clinical, radiologic, and induced sputum features of chronic obstructive pulmonary disease in nonsmokers: a descriptive study. Am J Respir Crit Care Med 2002; 166: 1078-1083.

24 Brightling CE, Monteiro W, Ward R, et al. Sputum eosinophilia and short-term response to prednisolone in chronic obstructive pulmonary disease: a randomised controlled trial. Lancet 2000; 356: 1480-1485.

25 Brightling CE, Monterio W, Green RH, et al. Induced sputum and other outcome measures in chronic obstructive pulmonary disease: safety and repeatability. Respir Med 2001; 95: 999-1002.

26 Brightling CE, McKenna S, Hargadon B, et al. Sputum eosinophilia and the short term response to inhaled mometasone in chronic obstructive pulmonary disease. Thorax 2005; 60: 193-198. 
27 Confalonieri M, Mainardi E, Della Porta R, et al. Inhaled corticosteroids reduce neutrophilic bronchial inflammation in patients with chronic obstructive pulmonary disease. Thorax 1998; 53: 583-585.

28 National Center for Health Statistics. Plan and operation of the Third National Health and Nutrition Examination Survey, 1988-94. Series 1: programs and collection procedures. Vital Health Stat 1 1994; No. 321-407.

29 Royston P, Ambler G, Sauerbrei W. The use of fractional polynomials to model continuous risk variables in epidemiology. Int J Epidemiol 1999; 28: 964-974.
30 Liberek T, Topley N, Jörres A, Coles GA, Gahl GM, Williams JD. Peritoneal dialysis fluid inhibition of phagocyte function: effects of osmolality and glucose concentration. J Am Soc Nephrol 1993; 3: 1508-1515.

31 Dorwart WV, Chalmers L. Comparison of methods for calculating serum osmolality from chemical concentrations, and the prognostic value of such calculations. Clin Chem 1975; 21: 190-194.

32 Fogarty AW, Jones S, Britton JR, Lewis SA, McKeever TM. Systemic inflammation and decline in lung function in a general population: a prospective study. Thorax 2007; 62: 515-520. 